\title{
Mucosal damage mediated by clostridial toxin in experimental clindamycin-associated colitis
}

\author{
G D ABRAMS,* M ALLO, G D RIFKIN, $\dagger$ R FEKETY, AND J SILVA, JR \\ From the Department of Pathology, Department of Surgery, and Division of Infectious Diseases, \\ Department of Internal Medicine, The University of Michigan, Ann Arbor, Michigan, USA
}

SUMMARY A toxin produced by Clostridium difficile has been implicated in the pathogenesis of antibiotic-associated colitis in humans and experimental animals. This study was undertaken in order to define the sequential evolution of caecal mucosal lesions in the hamster and to relate those lesions directly to the clostridial toxin. Sterile filtrates from a culture of $C$. difficile and from caecal contents of clindamycin-treated hamsters were studied with respect to their effects on the caecal mucosa and on cultured cell monolayers. The toxic filtrates both produced cellular swelling in vitro, and appeared to have a similar cytotoxic effect on caecal epithelial cells in vivo. Cellular damage was followed by extensive epithelial desquamation and the evolution of an acute pseudomembranous typhlitis. The pathogenetic sequence produced by the filtrates was identical with that previously described after direct clindamycin treatment. These findings demonstrate that intraluminal clostridial toxin can mediate development of the characteristic antibiotic-associated mucosal lesions.

Pseudomembranous colitis, first recognized many decades ago, has been described in a variety of clinical settings, but especially in association with the administration of antibiotics. ${ }^{2}$ Recently, hamsters treated with clindamycin have provided an excellent model of antibiotic-associated pseudomembranous colitis in humans. ${ }^{3-6}$ In this model, as well as in human cases, a toxin of clostridial origin has been identified ${ }^{37-12}$; and microbiological studies have implicated Clostridium difficile as the responsible organism. ${ }^{313-15}$ These converging lines of evidence suggest that antibiotic treatment alters the intestinal microflora in such a way as to allow C. difficile to flourish and produce a toxin which, in turn, may be responsible for the development of the mucosal lesions.

In the hamster, typhlitis has been produced by intracaecal injection of filtrates derived from caecal contents of clindamycin-treated animals, ${ }^{16}$ and by injection of stools from human patients with antibiotic-associated pseudomembranous colitis. ${ }^{13}$ Clostridia cultured from patients treated with clindamycin and experimental animals have likewise yielded toxin-containing filtrates capable of

*Address for correspondence and reprint requests: G D Abrams, Department of Pathology, The University of Michigan, $1335 \mathrm{E}$. Catherine, Ann Arbor, Michigan 48109 USA.

†Present address: Rockford School of Medicine, Rockford, Illinois, USA.

Received for publication 11 December 1979 inducing typhlitis after intracaecal injection. ${ }^{1316}$ In these studies, the presence of typhlitis was simply confirmed as an experimental end point, but the lesions themselves were not studied in detail or systematically compared with clindamycin induced lesions. The present work was undertaken in order to define the sequential stages in the evolution of typhlitis, to relate the lesions directly to the clostridial toxin, and to compare the toxin-induced lesions to those previously described after direct clindamycin treatment. Sterile filtrates from a culture of C. difficile and from caecal contents of clindamycin treated hamsters were injected intracaecally and compared with respect to their effects on the caecal mucosa. The filtrates were also compared with respect to their effects on cell monolayers in tissue culture.

\section{Methods}

EXPERIMENTAL ANIMALS

Five to 7 week old male Golden Syrian hamsters weighing $60-90 \mathrm{~g}$ were obtained from the Charles River Breeding Laboratories (Newfield, New Jersey). They were fed Teklad 1148 diet and provided with water ad libitum.

PREPARATION OF STOOL FILTRATES

Sterile filtrates were derived from pooled caecal 


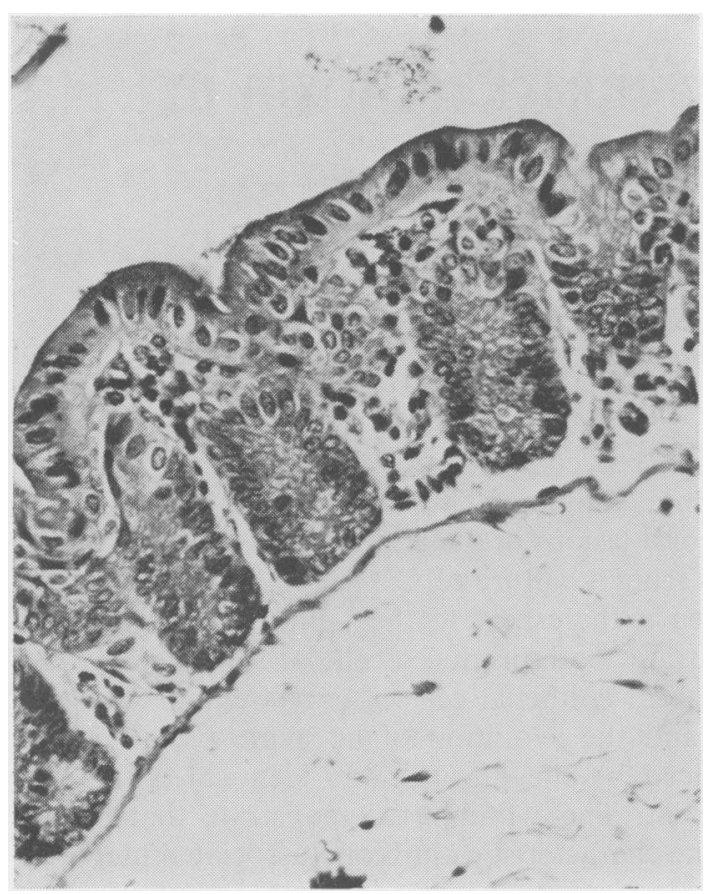

Fig. 1 Hamster caecum injected four hours previously with control stool filtrate. The mucosal surface is intact and the lamina propria is compact, with relatively few leucocytes. $H$ and $E, \times 208$. (The magnifications given in the Figures are the original ones.)

contents diluted 1:1 with saline, by means of centrifugation and millipore filtration as previously described..$^{10}$ One filtrate was prepared from animals killed when they had reached a moribund state after a single subcutaneous dose of clindamycin, $10 \mathrm{mg} / \mathrm{kg}$. A second filtrate, to serve as a control, was prepared from the caecal contents of animals given $0.5 \mathrm{ml}$ of $0.85 \%$ saline subcutaneously.

PREPARATION OF CULTURE FILTRATES

A strain of $C$. difficile, designated as 49a, was isolated from a hamster that died with typhlitis after treatment with clindamycin. The identity of this strain was established biochemically and by gas chromatography. ${ }^{17}$ The organism was grown anaerobically for 72 hours in BHI broth (Difco Laboratories, Detroit, Mich.). The cultures were clarified by centrifugation at $10000 \times \mathrm{g}$ for 30 minutes at $4^{\circ} \mathrm{C}$, and supernatants were sterilised by millipore filtration through $0.45 \mu$ membranes. Sterile BHI broth was used as a control substance.

SURGICAL PROCEDURES

Animals were randomly assigned to one of several

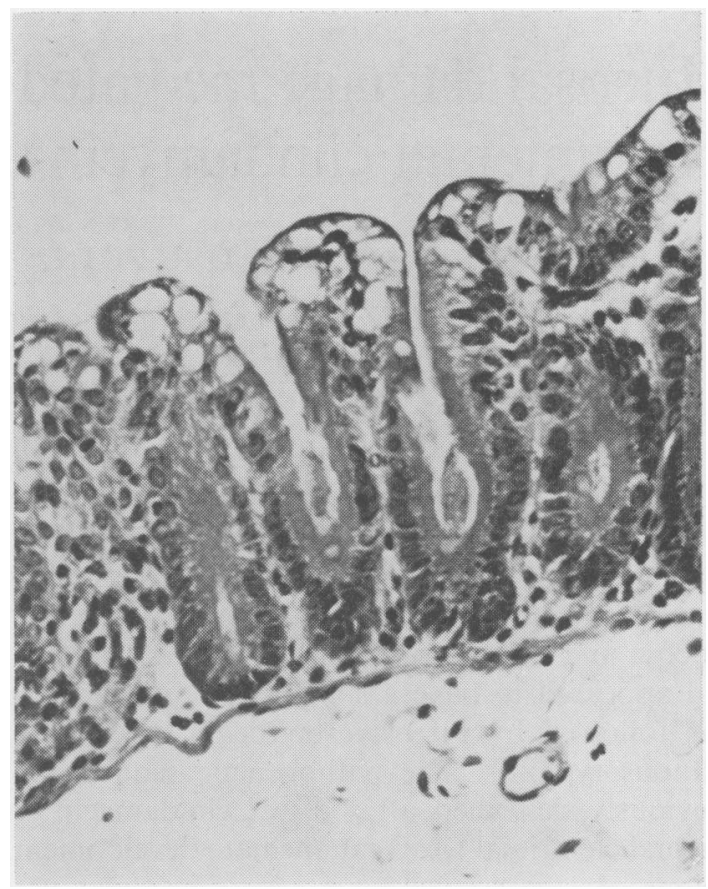

Fig. 2 Hamster caecum injected $2 \frac{1}{2}$ hours previously with a culture filtrate of $\mathrm{C}$. difficile. Cytoplasmic vacuolation in surface epithelial cells is evident. Note the presence of a gradient effect such that epithelial cells deeper in the crypts are unaffected. $H$ and $E, \times 208$.

experimental groups, and times of killing were designated. They were then anaesthetised with sodium pentobarbital $(80 \mathrm{mg} / \mathrm{kg})$ and injected intracaecally under direct vision with $3 \mathrm{ml}$ of stool filtrate, broth culture filtrate, or corresponding control materials. In one experiment, two animals of each group were scheduled for killing at postinjection intervals of $1,4,8,12$, and 24 hours. In this experiment however, animals receiving toxincontaining filtrates did not survive beyond 12 hours. In a second experiment, animals were injected intracaecally with culture filtrate or stool filtrate, and two animals of each group were killed at $1 \frac{1}{2}, 2 \frac{1}{2}$, $3 \frac{1}{2}$ hour intervals in order to study early epithelial changes. Control animals in this experiment received a mixture of filtrate and an equine antitoxin against Clostridium sordellii toxin (US Bureau of Biologicals), known to cross-react with $C$. difficile toxin.

TISSUE SAMPLING AND PROCESSING

At the designated intervals, animals were killed by decapitation and their caeca removed in toto. Each caecum was bisected, emptied, rinsed in $0.85 \%$ 


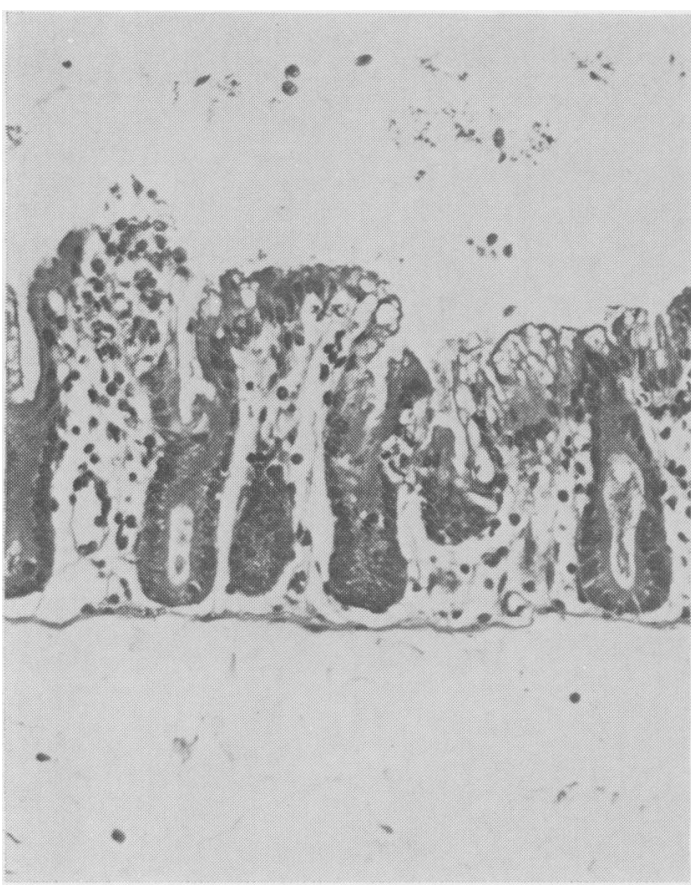

Fig. 3 Hamster caecum injected $2 \frac{1}{2}$ hours previously with a stool filtrate from a clindamycin-treated animal. Vacuolar changes similar to those in Fig. 2 are evident. In addition, at the left is a 'summit' lesion consisting of polymorphonuclear leucocytes aggregated beneath an epithelial defect. $H$ and $E, \times 208$.

saline, and then fixed in $10 \%$ formalin. Samples of fixed tissues were processed for light microscopy by paraffin embedding, sectioning, and staining with haematoxylin and eosin. Samples for scanning electron microscopy were pinned onto paraffin blocks, dehydrated in graded ethanol, and criticalpoint dried from an amyl acetate- $\mathrm{CO}_{2}$ mixture. Specimens were then gold coated and examined with a JSMU 3 scanning electron microscope (Japan Electron Optics Lab, Medford, Mass.).

\section{TISSUE CULTURE TECHNIQUES}

Monolayers of $\mathrm{CV}-1$ monkey kidney cells were grown on glass coverslips in Delbecco's modified Eagle medium at $37^{\circ} \mathrm{C}$ until confluent. The coverslips were then placed into individual wells of multiwell tissue culture plate (Falcon 3008), maintained in the same medium, and exposed to $100 \mu \mathrm{l}$ of stool filtrate or culture filtrate. The cells were then fixed in $2 \%$ glutaraldehyde at intervals of $3 \frac{1}{2}, 5 \frac{1}{2}$, and 24 hours of exposure. The coverslips were dehydrated and prepared for scanning electron microscopy as described above.

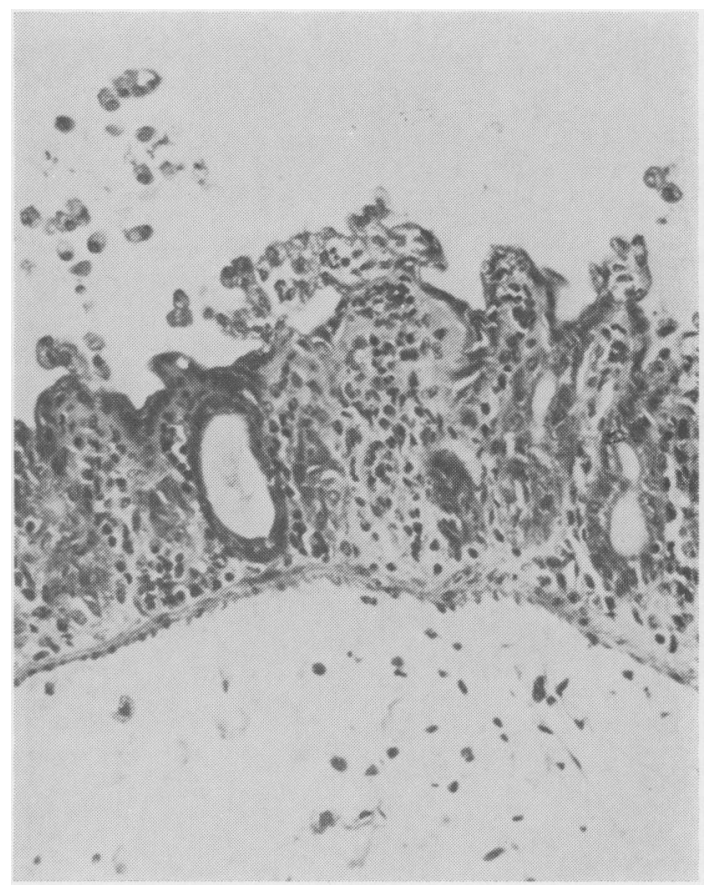

Fig. 4 Hamster caecum injected eight hours previously with a stool filtrate from a clindamycin-treated animal. Damaged surface epithelial cells have already desquamated or are desquamating in irregular vertical ridges. Note the relative sparing of epithelial cells deeper in the mucosa. Leucocytes are increased in number in submucosa and lamina propria. $H$ and $E$, $\times 208$.

\section{Results}

ANIMALS INJECTED WITH CONTROL FILTRATES

The appearance of the caecum was similar in ainmals injected with sterile BHI broth and in those injected with stool filtrates from saline treated animals. At one hour after injection submucosal oedema had begun to develop, and by four hours scattered leucocytes were present, extending from the serosa to the submucosa. This minimal reaction peaked at eight hours and appeared to diminish at the 12 and 24 hour intervals. The caecal mucosa was intact at all times, save for evidence of local trauma at the injection site. There was no evidence of diffuse epithelial damage or mucosal typhlitis (Fig. 1).

\section{ANIMALS INJECTED WITH TOXIC}

FILTRATES

The sequence of caecal mucosal changes produced by 


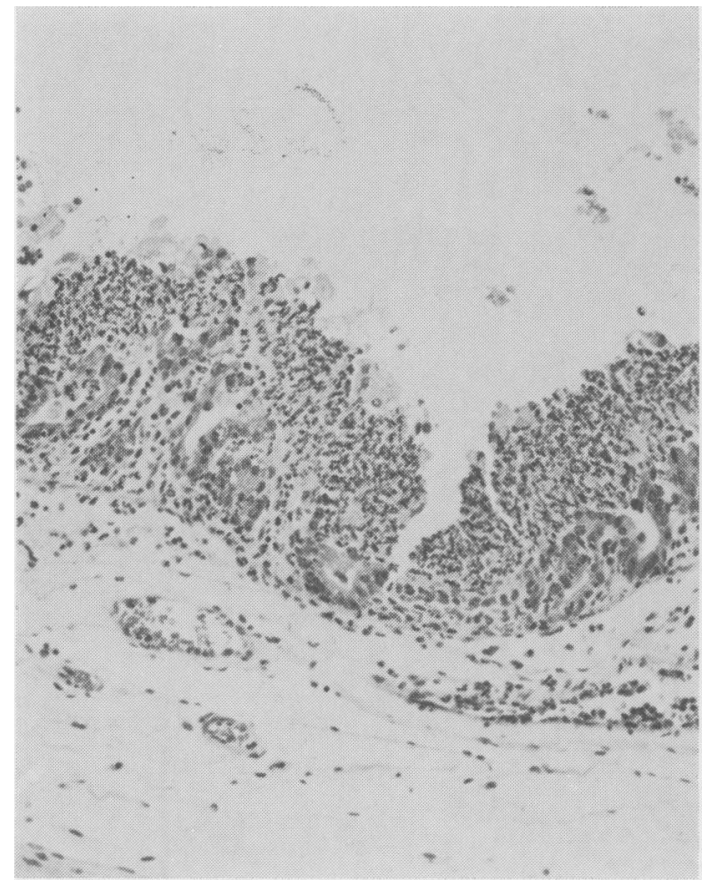

Fig. 5 Hamster caecum injected eight hours previously with a culture filtrate of $\mathrm{C}$. difficile. Severely damaged mucosa, necrotic in its superficial half, is surfaced by inflammatory pseudomembrane. Some deeper portions of crypts still survive. $H$ and $E, \times 132$.

the culture filtrate of $C$. difficile precisely paralleled that produced by the stool filtrate from clindamycintreated hamsters. In both instances, the evolving histological pattern reflected the direct action of an injurious substance on the surface epithelium of the caecal mucosa, leading to a diffuse typhlitis with inflammatory pseudomembranes. The following description of evolving mucosal lesions applies both to stool filtrate and culture filtrate.

The caecal mucosa was histologically normal for the first hour after injection. Between 60 and 90 minutes, surface epithelial cells between crypts developed cytoplasmic vacuolation which progressed in extent during the $2 \frac{1}{2}$ to $3 \frac{1}{2}$ hour interval. This cytological change was most pronounced in epithelial cells closest to the lumen, while more deeply situated crypt epithelial cells were generally not involved (Fig. 2). This epithelial abnormality was not seen in animals receiving filtrates neutralised with antitoxin.

When the epithelial vacuolation first appeared, the lamina propria remained normal. Between $2 \frac{1}{2}$ and four hours, purulent inflammation began to appear in areas of severe epithelial damage, particularly in

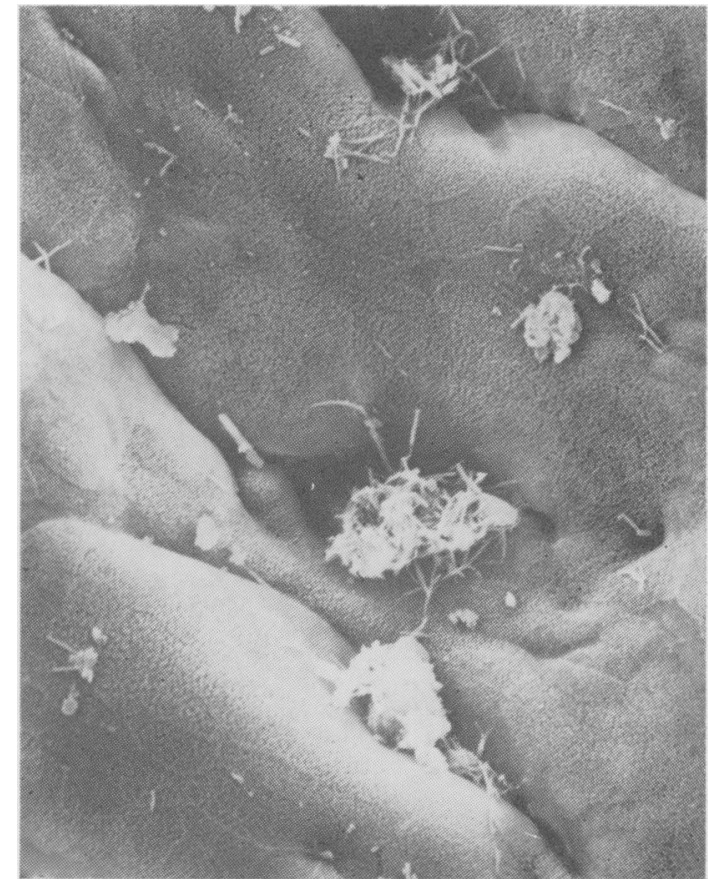

Fig. 6 Hamster caecum injected four hours previously with sterile BHI broth. The luminal surfaces of caecal epithelial cells are flat and regular. The microvillous contour is even. Scanning electron micrograph, $\times 1000$.

the 'summits' between crypts (Fig. 3). At four hours, surface epithelial cells were severely distorted, ballooned, and beginning to desquamate into the lumen in small clusters or vertically oriented ridges. Adjacent areas of the mucosa were often surfaced by flattened epithelial cells which appeared to be spreading as neighbouring cells desquamated. The lamina propria of these damaged mucosae appeared congested, and increasing purulent inflammation was evident.

These epithelial changes and the associated inflammatory reaction evolved at a somewhat variable pace over the next several hours. By eight hours after injection, a severe diffuse typhlitis was evident in all animals. Some parts of the mucosa were surfaced by an attenuated epithelium which extended beneath clusters and ridges of damaged, desquamating epithelial cells mixed with purulent exudate (Fig. 4). In other areas, superficial portions of the mucosa were necrotic and sloughing, and the surface was covered by an inflammatory pseudomembrane (Fig. 5).

Scanning electron microscopy revealed changes in mucosal topography corresponding to those seen in light microscopy. In control animals, the caecal 


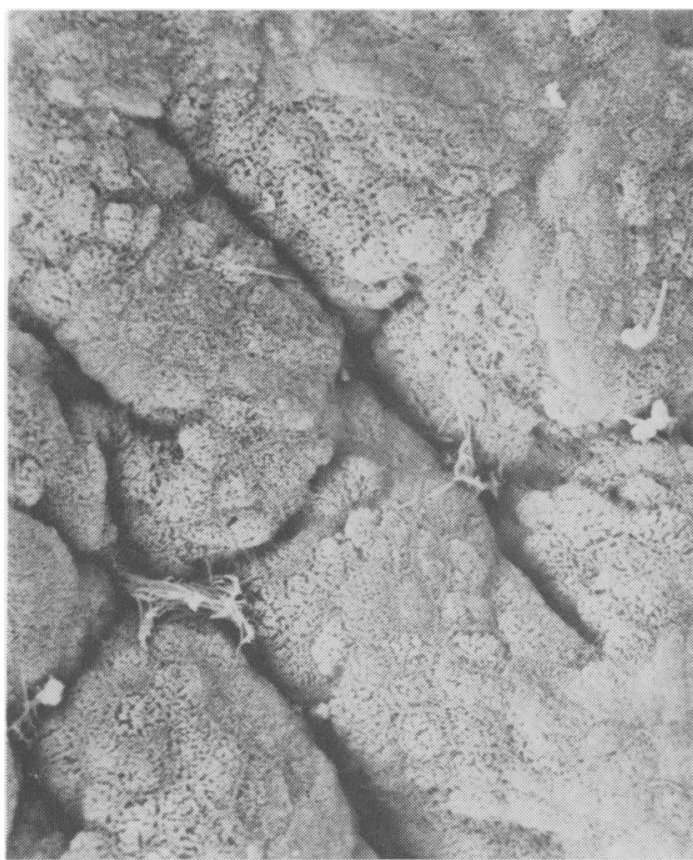

Fig. 7 Hamster caecum injected $3 \frac{1}{2}$ hours previously with a stool filtrate from a clindamycin-treated animal. The surface contour of this mucosa is somewhat nodular, apparently due to swelling of cells. Intercellular junctions are thus accentuated. Scanning electron micrograph, $\times 1000$.

mucosal surface was smooth and regular, with an even microvillous pattern (Fig. 6). In animals injected with toxic filtrates, the earliest recognisable change consisted of apparent swelling of surface epithelial cells, which became more convex and more sharply demarcated at lines of intercellular junction than in the corresponding control mucosae (Fig. 7). As the lesions progressed, crypts were dilated and the intercryptal 'summit' regions were ridged with severely distorted, desquamating epithelial cells (Fig. 8). Finally, topographical features were obscured by overlying necrotic debris and inflammatory exudate.

\section{CV-1 MONKEY KIDNEY CELLS EXPOSED in vitro TO TOXIC FILTRATES}

Scanning electron microscopy of cells exposed in vitro to faecal and culture filtrates supported the inference, drawn from the above observations, that these filtrates contain a toxin which is capable of injuring cells directly. Control cells were smooth surfaced and relatively flat, while those exposed to the filtrates developed an irregular contour and became ballooned, much as did the caecal epithelial cells (Figs. 9 and 10).

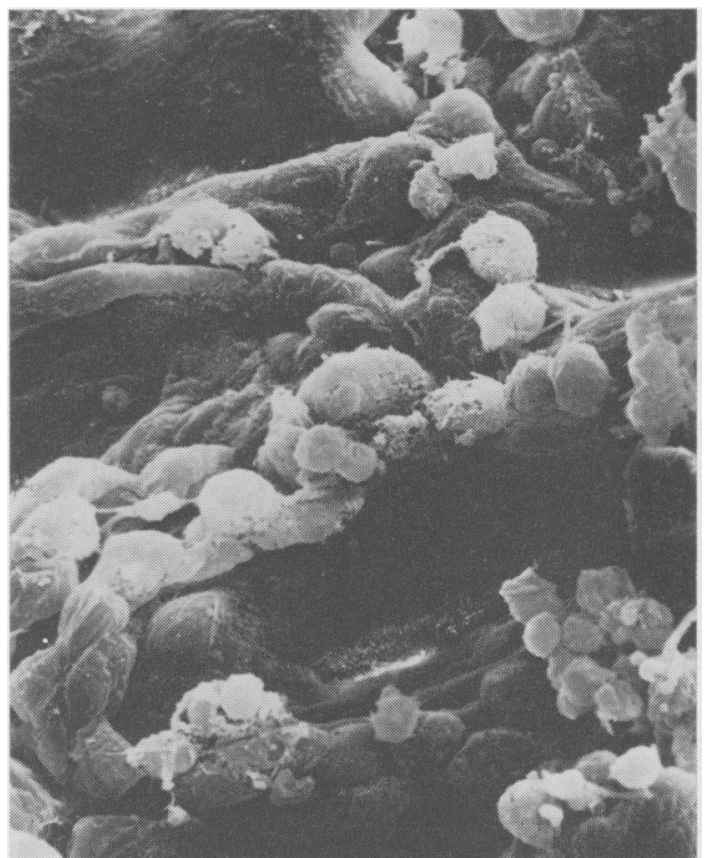

Fig. 8 Hamster caecum injected four hours previously with a stool filtrate from a clindamycin-treated animal. Damaged epithelial cells are desquamating from the mucosal surface. This appearance corresponds to that shown in Fig. 4. Scanning electron micrograph, $\times 1000$.

\section{Discussion}

Recent investigations have documented the presence of $C$. difficile and its toxin in the faeces of patients with antibiotic-associated pseudomembranous

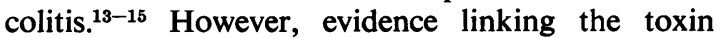
directly to the pathogenesis of the human colitic lesion has, of necessity, been incomplete. The clindamycin-treated hamster has proved, in the hands of several groups of investigators, to be a useful model for the study of this disease. ${ }^{356}$ In our own laboratory, the sequence of studies began with the discovery of a toxin in the stools of patients with antibiotic-associated colitis, confirming the original report of Larson. ${ }^{7}{ }^{9}$ The toxin, which was lethal for hamsters when injected intraperitoneally, and which was directly toxic to cultured cells, could be neutralised by $C$. sordellii antitoxin. Turning to the clindamycin-treated hamster, we characterised the intestinal lesions by light and scanning electron microscopy, and found them to be associated with an increase in $C$. sordellii and $C$. difficile in the faeces. ${ }^{4}$ Vancomycin was found to prevent these clindamycin-induced lesions. ${ }^{18}$ Subsequently, it was 


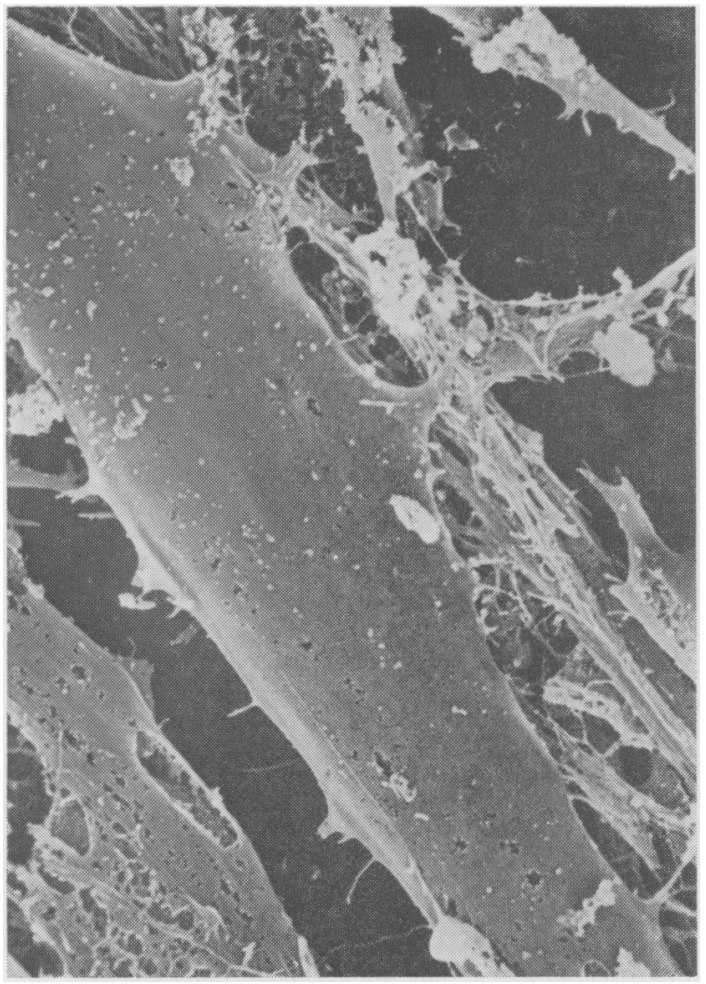

Fig. $9 C V$-1 monkey kidney cell in control monolayer not exposed to toxin. The surface of the cell is smooth and regular. Scanning electron micrograph, $\times 3000$.

found that a toxic substance was present in the faeces of clindamycin-treated hamsters which was lethal to other hamsters and cytotoxic in tissue culture. The toxic effects were neutralised by in vitro incubation with polyvalent clostridial antitoxin..$^{10}$ Next it was found that neutralisation of the hamster toxin could be accomplished with $C$. sordellii antitoxin, and that the antitoxin would neutralise the toxicity of culture filtrates of $C$. difficile as well as $C$. sordellii. ${ }^{11}$ The former organism appeared more likely to be responsible for the disease produced by clindamycin. Finally, it was recently demonstrated in our laboratory that passive immunisation of the hamster with $C$. sordellii antitoxin is protective against clindamycin-associated colitis. ${ }^{12}$ The mechanism by which the toxin acts on the mucosa is largely unknown, and the details of histogenesis have not been reported heretofore.

In the studies reported here, filtrates of caecal content from clindamycin-treated animals and culture filtrates of $C$. difficile, upon intracaecal injection, produced a severe, diffuse typhlitis. The evolving lesions were indistinguishable from those

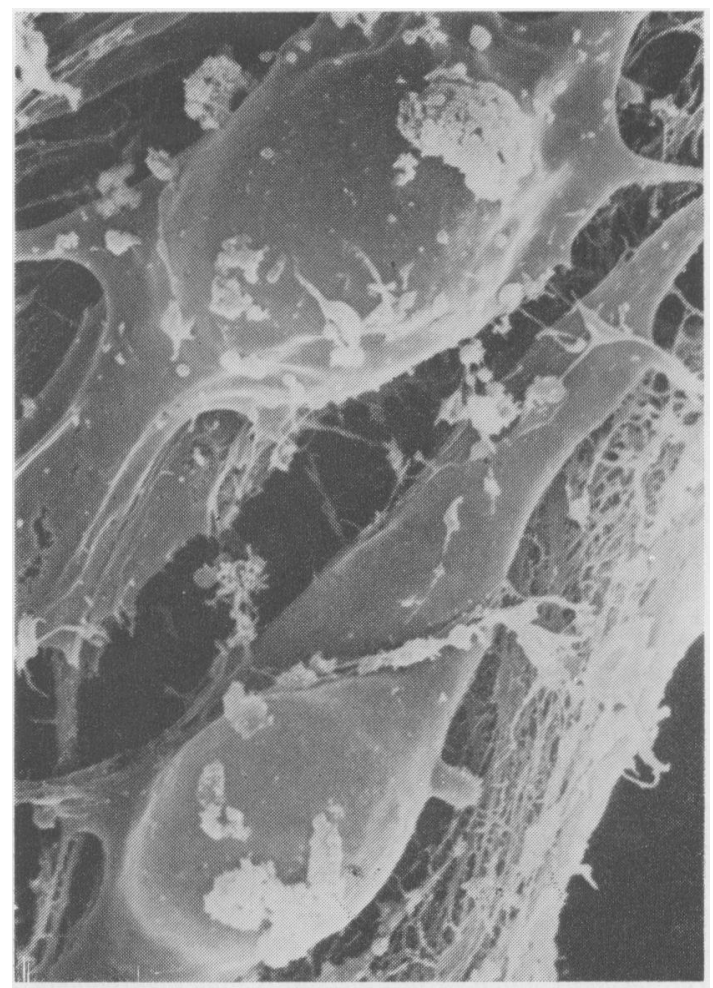

Fig. $10 C V$-1 monkey kidney cells in monolayer exposed for $5 \frac{1}{2}$ hours to a culture filtrate of $\mathrm{C}$. difficile. The cells are obviously swollen and irregularly rounded. Scanning electron micrograph, $\times 3000$.

seen in clindamycin-treated animals by light and scanning electron microscopy. ${ }^{45}$ The earliest detectable lesion produced by the toxic filtrates was a striking epithelial swelling and vacuolation which occurred in the absence of other mucosal abnormalities. This, taken in conjunction with the superficial location of the affected cells, is most consistent with the effects of a luminal toxin acting directly on epithelium. That the toxin can indeed produce such direct effects is shown by the results of our tissue culture studies, and those of others. In vitro cytotoxicity has been demonstrated with faeces from patients ${ }^{7}$ and experimental animals ${ }^{3}$ with antibiotic-associated colitis. The results of a recent study suggest that one of the main effects of C. difficile toxin is modification of the cell membrane. ${ }^{19} \mathrm{~A}$ similar pattern of direct toxic effects on superficial intestinal epithelium has been reported for another clostridium, $C$. perfringens. ${ }^{20}$

Epithelial cells injured by the toxin desquamate rapidly, sometimes en masse, and an acute inflammatory reaction evolves in the subjacent lamina propria. The thinning and flattening of epithelium 
next to the masses of desquamating cells most probably represents early reparative migration of less damaged cells. At the peak of development of the typhlitis, epithelial loss becomes sufficiently massive for mucosal continuity to be lost, and the surface is coated by an inflammatory pseudomembrane.

Thus, our entire series of studies of the experimental hamster model, in agreement with abundant evidence adduced by others 51316 supports and extends the evidence derived from human cases. Clindamycin-treatment is associated with the growth of $C$. difficile in the intestine and with the production of toxin by the organism. The intraluminal toxin mediates the development of the characteristic mucosal lesions.

This study was supported in part by the Upjohn Company (Kalamazoo, Mich.), by a grant from the National Institutes of Health (1-ROI-AM 21076-01), and by the Frederick Novy Infectious Diseases Research Fund (The University of Michigan).

\section{References}

${ }^{1}$ Price AB, Davies DR. Pseudomembranous colitis. J Clin Pathol 1977; 30: 1-12.

${ }^{2}$ Bartlett JG, Gorbach SL. Pseudomembranous enterocolitis (antibiotic-related colitis). Adv Intern Med 1977; 22: 455-76.

${ }^{3}$ Chang TW, Bartlett JG, Gorbach SL, Onderdonk AB. Clindamycin-induced enterocolitis in hamsters as a model of pseundomembranous colitis in patients. Infect Immun 1978; 20: 526-9.

${ }^{4}$ Lusk RH, Fekety R, Silva J, Browne RA, Ringler DH, Abrams GD. Clindamycin-induced enterocolitis in hamsters. J Infect Dis 1978; 137: 464-75

${ }^{5}$ Humphrey CD, Lushbaugh WB, Condon CW, Pittman JC, Pittman FE. Light and electron microscopic studies of antibiotic-associated colitis in the hamster. Gut 1979; 20: 6-15.

${ }^{6}$ Price AB, Larson HE, Crow J. Morphology of experimental antibiotic-associated enterocolitis in the hamster: a model for human pseudomembranous colitis and antibiotic-associated diarrhoea. Gut 1979; 20: 467-75.
${ }^{7}$ Larson HE, Parry JV, Price AB, Davies DR, Dolby J, Tyrell DAJ. Undescribed toxin in pseudomembranous colitis. Br Med J 1977; 1 : 1246-8.

${ }^{8}$ Larson HE, Price AB. Pseudomembranous colitis: presence of clostridial toxin. Lancet $1977 ; 2$ : 1312-4.

${ }^{9}$ Rif kin GD, Fekety FR, Silva J, Jr, Sack RB. Antibioticinduced colitis: implication of a toxin neutralised by Clostridium sordellii antitoxin. Lancet 1977; 2: 1103-6.

${ }^{10}$ Rifkin GD, Silva J, Jr, Fekety R. Gastrointestinal and systemic toxicity of fecal extracts from hamsters with clindamycin-induced colitis. Gastroenterology 1978; 74: 52-7.

${ }^{11}$ Rifkin GD, Fekety R, Silva J, Jr. Neutralization by Clostridium sordellii antitoxin of toxins implicated in clindamycin-induced cecitis in the hamster. Gastroenterology 1978; 75: 422-4.

${ }^{12}$ Allo M, Silva J, Jr, Fekety R, Rif kin GD, Waskin H. Prevention of clindamycin-induced colitis in hamsters by Clostridium sordellii antitoxin. Gastroenterology 1979; 76: 351-5.

${ }^{13}$ Bartlett JG, Chang TW, Gurwith M, Gorbach SL, Onderdonk AB. Antibiotic-associated pseudomembranous colitis due to toxin-producing clostridia. N Engl J Med 1978; 298: 531-4.

${ }^{14}$ George RH, Symonds JM, Dimock F, et al. Identification of Clostridium difficile as a cause of pseudomembranous colitis. $\mathrm{Br}$ Med J 1978; 1: 695.

${ }^{15}$ Larson HE, Price AB, Honour P, Borriello SP. Clostridium difficile and the aetiology of pseudomembranous colitis. Lancet 1978; 1 : 1063-6.

${ }^{16}$ Bartlett JG, Onderdonk AB, Cisneros RL, Kasper DL. Clindamycin-associated colitis due to a toxin-producing species of Clostridium in hamsters. J Infect Dis 1977; 136: 701-5.

${ }^{17}$ Fekety R, Silva J, Toshniwal R, et al. Antibioticassociated colitis: effect of antibiotics on Clostridium difficile and the disease in hamsters. Rev Infect Dis 1979; 1: 386-96.

${ }^{18}$ Browne RA, Fekety R, Jr, Silva J, Jr, Boyd DI, Work $\mathrm{CO}$, Abrams GD. The protective effect of vancomycin on clindamycin-induced colitis in hamsters. $J$ Hopk Med J 1977; 141: 183-92.

${ }^{19}$ Chang TW, Lin PS, Gorbach SL, Bartlett JG. Ultrastructural changes of cultured human amnion cells by Clostridium difficile toxin. Infect Immun 1979; 23: 795-8.

${ }^{20}$ McDonel JL, Chang LW, Pounds JG, Duncan CL. The effects of Clostridium perfringens enterotoxin on rat and rabbit ileum. Lab Invest 1978; 39: 210-8. 